\title{
A (IN)CONSTITUCIONALIDADE DA ALÍQUOTA NA REGRA-MATRIZ DE INCIDÊNCIA TRIBUTÁRIA DO ICMS SOBRE A CIRCULAÇÃO DE ENERGIA ELÉTRICA NO RICMS/ES
}

\section{Larissa Takla de Biase Nogueira*}

Resumo: A pesquisa tem como objetivo efetuar uma análise da alíquota, enquanto componente quantitativo da regra-matriz de incidência tributária do ICMS sobre a circulação de energia elétrica no RICMS/ES, à luz dos princípios constitucionais da seletividade pela essencialidade do bem e da isonomia tributária. Pretende-se, por meio da adoção de uma abordagem dialética e de uma ampla pesquisa bibliográfica, tecer considerações sintáticas, porém primordiais, acerca da estrutura e dos componentes lógicos da regra-matriz, bem como dos citados princípios. Em seguida, será verificada a adequação da alíquota no caso examinado aos elencados ditames, de forma a verificar a sua constitucionalidade.

Palavras-chave: ICMS; alíquota, energia elétrica; princípio da seletividade; princípio da isonomia tributária

\section{THE (UN)CONSTITUTIONALITY OF THE TAX RATE OF THE ICMS ON THE CIRCULATION OF ELECTRICITY IN THE RICMS/ES}

\begin{abstract}
This research conducts a critical analysis of the tax rate, as a quantitative component of the ICMS on the circulation of electricity in the RICMS/ES, considering the constitutional principles of selectivity and tax isonomy. It is intended to make syntactic but primordial considerations about the structure and logical components of the tax rule, as well as of the aforementioned principles, through a dialectical approach and an extensive bibliographical research. In the end, the study aims the provide an answer regarding the adequacy of the tax rate in this case to the principles mentioned and its constitutionality.
\end{abstract}

Keywords: ICMS; tax rate; electricity; principle of selectivity; principle of tax isonomy

\section{INTRODUÇÃO}

Dentro do sistema tributário brasileiro, o Imposto sobre Circulação de Mercadorias ("ICMS") desponta como um dos tributos de maior complexidade, cujo estudo demanda verdadeiro confronto entre princípios e normas constitucionais e infraconstitucionais. Neste contexto, principalmente por se tratar de um tributo da competência tributária dos Estados, com tratamento legislativo diferenciado e esparso conforme cada ente estadual, surgem inúmeros questionamentos quanto à constitucionalidade ou legalidade da norma jurídica tributária estabelecida por cada ente legislativo, conforme o caso.

\footnotetext{
* Mestranda em Direitos e Garantias Fundamentais pela Faculdade de Direito de Vitória (FDV). Especialista em Direito Tributário pelo Instituto Brasileiro de Direito Tributário (IBET). Graduada em Direito pela Universidade Federal do Espírito Santo (UFES). Advogada. E-mail: larissadebiase@ gmail.com.
} 
A presente pesquisa, assim, pretende efetuar uma análise da regra-matriz de incidência tributária do ICMS incidente sobre a circulação de energia elétrica, mercadoria esta de uso geral e de enorme importância no mundo atual, tanto nas atividades industriais e comerciais quanto para os contribuintes pessoas físicas de todos os níveis de renda.

Nesta seara, almeja-se, especificamente, até mesmo pela limitação de extensão deste trabalho, realizar um corte metodológico a fim de examinar a referida norma dentro do contexto do Regulamento do ICMS do Estado do Espírito Santo ("RICMS/ES"). Em seguida, será proposto um novo corte metodológico quanto aos critérios da aludida regra jurídica que serão levados em consideração, haja vista que o presente trabalho tratará tão somente da alíquota, um dos critérios quantitativos do imposto em questão, justamente os de maior impacto, financeiramente falando, em relação aos contribuintes.

Destarte, elegeu-se, como problema de pesquisa, a seguinte indagação: “a alíquota, dentro da regra-matriz de incidência tributária do ICMS sobre a circulação de energia elétrica estabelecida no RICMS/ES, observa os princípios constitucionais da seletividade em função da essencialidade do bem e da isonomia tributária?".

Para tal análise, será adotada nesta monografia uma abordagem dialética, bem como uma ampla pesquisa bibliográfica, de modo a cotejar não só a legislação, mas também materiais publicados em livros, artigos e teses inseridos na conjuntura da Teoria Geral do Direito Tributário e dos Sistemas e Princípios Constitucionais Tributários. Salienta-se, entretanto, desde logo, que o estudo será conduzido dentro das premissas de base da regramatriz de incidência tributária na forma preconizada por Paulo de Barros Carvalho, referencial teórico aqui adotado.

Feitas estas considerações, o presente trabalho será dividido de modo a tratar, inicialmente, dos componentes lógicos da regra-matriz na forma proposta, para então, posteriormente, em secções subsequentes, analisar, em específico, o critério quantitativo da alíquota dentro da regra-matriz do ICMS sobre a circulação de energia elétrica no RICMS/ES e o seu respectivo atendimento aos princípios constitucionais da seletividade pela essencialidade do bem e da isonomia tributária. Ao final, concluído o aludido exame, será então formado um juízo acerca da (in)constitucionalidade desta regra-matriz no âmbito do RICMS/ES em resposta à problemática levantada, bem como, em adição, sugerido um critério quantitativo correspondente que melhor se amolde ao tratamento constitucional do tema. 
2 BREVE ANÁliSE DA ESTRUTURA E DOS COMPONENTES LÓGICOS DA REGRA-MATRIZ DE INCIDÊNCIA TRIBUTÁRIA

A incidência de determinado tributo a um evento jurídico tributário ${ }^{1}$ é determinada pela norma tributária em sentido estrito, a qual se apresentará como um juízo hipotéticocondicional, formado por uma hipótese e um consequente ${ }^{2}$, unidos entre si por um modal dêontico (dever-ser). A esta norma jurídica a melhor doutrina denomina regra-matriz de incidência tributária (CARVALHO, 2014). Nas palavras de Paulo de Barros Carvalho:

A criação de um esquema seguro para dar parâmetros racionais à tributação, com
fundamento em estrutura lógica, permitiu à Ciência do Direito Tributário colaborar
na limitação da vontade arrecadatória do legislador. A regra-matriz veio à lume,
justamente, para instaurar critérios seguros, permitindo identificar a natureza do
tributo e relacioná-la com o regime jurídico que querem lhe impor. O texto de lei
passa a ser observado de forma crítica e sob reflexões autorizadas pela
Epistemologia Geral, de tal sorte que fiquem preservados os sobranceiros princípios
constitucionais informadores da adequada construção da regra-matriz de incidência,
assim como de todas as unidades integrantes do processo de positivação do direito
$(2015$, p. 690).

Sobre a regra-matriz de incidência tributária, Aurora Tomazini, oportunamente, aduz:

\begin{abstract}
$\mathrm{Na}$ expressão 'regra-matriz de incidência' emprega-se o termo "regra" como sinônimo de norma jurídica, porque trata-se de uma construção do intérprete, alcançada a partir do contato com os textos legislados. O termo 'matriz' é utilizado para significar que tal construção serve como modelo padrão sintático-semântico na produção da linguagem jurídica concreta. E "de incidência", porque se refere a normas produzidas para serem aplicadas (2009, p. 362).
\end{abstract}

Pelo exposto, em outras palavras, conclui-se que a regra-matriz de incidência tributária constitui verdadeira fórmula que expõe e simplifica o feixe normativo do tributo. Percebe-se, portanto, que na regra-matriz estão contidos todos os critérios aptos a identificar os elementos necessários à incidência de determinado tributo, motivo pelo qual o estudo dessa norma deve levar em consideração não somente os componentes postos pelo legislador ordinário, mas também todos os princípios e limites elencados na Carta Magna para o exercício dessa competência tributária.

\footnotetext{
${ }^{1}$ A expressão evento jurídico tributário é aqui empregada no sentido adotado pelo jurista Paulo de Barros Carvalho: “(...) fato que realmente se sucede no quadro do relacionamento social, dentro de específicas condições de espaço e de tempo, que podemos captar por meio de nossos órgãos sensoriais, e até dele participar fisicamente (...)" (CARVALHO, 2014, p. 256).

${ }^{2}$ Ou ainda, na nomenclatura alternativa sugerida pelo Professor Paulo de Barros Carvalho, descritor (hipótese) e prescritor (consequente), dentre outros termos assimilados. (2014, p. 239).
} 
Passa-se, neste momento, a uma resumida análise de cada um dos componentes lógicos de tal norma a fim de estabelecer os necessários pressupostos para o problema proposto.

Nestes termos, adentrando nesta análise, a hipótese de incidência tributária é assim definida por um dos principais estudiosos do tema:

(..) esse descritor, que é o antecedente ou suposto da norma, está imerso na linguagem prescritiva do direito positivo, porque, mesmo formulado por um conceito de teor descritivo, vem atrelado à consequência da regra, onde reside a estipulação da conduta (prescritor), meta finalística e razão da própria existência do direito. Por isso, os conceitos jurídicos veiculados na hipótese não estão sujeitos aos valores de verdade ou falsidade, como as proposições descritivas que os cientistas emitem. As hipóteses das normas jurídicas valem ou não valem, como também as respectivas consequências (prescritores) têm validade ou invalidade. Ao escolher os fatos que lhe interessam como pretexto para desencadear efeitos jurídicos, o legislador expede conceitos que selecionam propriedades do evento (CARVALHO, 2014, p. 261-262).

Observa-se, desse modo, que a chamada hipótese é a situação descrita pelo legislador, com a indicação de seus elementos básicos, que, quando verificados, possuirão a aptidão para produzir os efeitos determinados no consequente. Consitui-se, portanto, a hipótese de incidência, como um verdadeiro seletor de propriedades para a delimitação do fato jurídico tributável. Como tal, a hipótese conterá três critérios identificadores do fato ${ }^{3}$ : o critério material, o critério espacial e o critério temporal ${ }^{4}$.

O primeiro deles, isto é, o critério material, "consiste no verbo ensejador da imposição tributária” (KFOURI JR., 2016, p. 237), seguido de um complemento, de forma a delimitar a ação objeto da incidência da norma, que pode ser tanto um fazer, quanto um dar ou, ainda, apenas um ser (CARVALHO, 1974).

Ainda, nas palavras de Auror Tomazini de Carvalho, este critério "é o feixe de informações contidas na hipótese normativa que nos permite identificar, com exatidão, o momento de ocorrência do evento a ser promovido à categoria de fato jurídico" $(2009$, p. $380)$.

\footnotetext{
${ }^{3}$ Segundo a definição de Paulo de Barros Carvalho, fato jurídico tributário é "o relato linguístico desse acontecimento. Fato jurídico porque tem o condão de irradiar efeitos de direito. E tributário pela simples razão de que sua eficácia está diretamente ligada à instituição do tributo" (2014, p. 256).

${ }^{4}$ Nos dizeres de Paulo de Barros Carvalho: "Ao conceituar o fato que dará ensejo ao nascimento da relação jurídica do tributo, o legislador também seleciona as propriedades que julgou importantes para caracterizá-lo. E, desse conceito, podemos extrair critérios de identificação que nos permitam reconhecê-lo toda vez que, efetivamente, aconteça. No enunciado hipotético vamos encontrar três critérios identificadores do fato: a) critério material; b) critério espacial; e c) critério temporal". (2014, p. 262).
} 


\title{
A (IN)CONSTITUCIONALIDADE DA ALÍQUOTA NA REGRA-MATRIZ DE INCIDÊNCIA TRIBUTÁRIA DO ICMS SOBRE A CIRCULAÇÃO DE ENERGIA ELÉTRICA NO RICMS/ES
}

Evidentemente, a esta ação, a fim de ser corretamente identificada no mundo factual, deverá ser atribuído um componente lógico espacial e um temporal. ${ }^{5}$

Neste contexto, o critério espacial são os elementos indicadores das condições de espaço em que se dará a incidência da regra-matriz, podendo apresentar-se como uma menção direta a certa localidade para tal ou aludir a um espaço específico, só se verificando o fato típico se dentro deste limite geográfico. Além dessas duas possibilidades, há uma última, mais genérica, por meio da qual os eventos jurídicos tributários que forem verificados no local de vigência da regra-matriz desencadearão seus efeitos (CARVALHO, 2014).

Por fim, tem-se o critério temporal como o último componente lógico da hipótese de incidência. Sobre este critério, alude-se à definição de Paulo de Barros Carvalho:

\begin{abstract}
Compreendemos o critério temporal da hipótese tributária como o grupo de indicações, contidas no suposto da regra, e que nos oferecem elementos para saber, com exatidão, em que preciso instante acontece o fato descrito, passando a existir o liame jurídico que amarra devedor e credor, em função de um objeto - o pagamento de certa prestação pecuniária (2014, p. 268).
\end{abstract}

Destarde, este critério fixará a unidade de tempo para situar o momento em que, verificada a ocorrência do disposito no critério material dentro dos limites territoriais estabelecidos no critério espacial, será verificado o fato sobre o qual incidirá a regra-matriz.

Feitas tais considerações sobre a hipótese de incidência, passa-se à análise do consequente da regra-matriz. Nas palavras de Paulo de Barros Carvalho, o consequente de uma norma jurídica é assim determinado:

(...) o prescritor da norma é, invariavelmente, uma proposição relacional, enlaçando dois ou mais sujeitos de direito em torno de uma conduta regulada como proibida, permitida ou obrigatória. Trata-se de uma relação entre termos determinados, que são necessariamente pessoas: S' R S'. Nessa fórmula, S' é uma pessoa qualquer e S' é uma pessoa qualquer, desde que não seja $S$ '. R é o relacional deôntico, aparecendo

\footnotetext{
${ }^{5} \mathrm{O}$ autor Paulo de Barros Carvalha teceu críticas à confusão entre tais critérios e o aspecto material, advinda da impropriedade terminológica incorrida por diversos autores nacionais: "Por abstração, desliguemos aquele proceder dos seus condicionantes espaço-temporais, a fim de analisá-lo de modo particular, nos seus traços de essência. Sobre esse assunto, aliás, é curioso anotar que os autores deparam com grande dificuldade para promover o isolamento do critério material, que designam por elemento material do fato gerador, elemento objetivo do fato gerador ou por aspecto material da hipótese de incidência. Tanto nacionais como estrangeiros tropeçam, não se livrando de apresentá-lo engastado aos demais aspectos ou elementos integradores do conceito, e acabam por desenhar, como critério material, todo o perfil da hipótese tributária. Nesse vício de raciocínio incorreram quantos se dispuseram, em trabalho de fôlego, a mergulhar no exame aprofundado do suposto. Impressionados com a impossibilidade física de separar o inseparável, confundiram o núcleo da hipótese normativa com a própria hipótese, definindo a parte pelo todo, esquecidos de que lidavam com entidades lógicas, dentro das quais é admissível abstrair em repetidas e elevadas gradações. É muito comum, por isso, a indevida alusão ao critério material, como a descrição objetiva do fato. Ora, a descrição objetiva do fato é o que se obtém da compostura integral da hipótese tributária, enquanto o critério material é um dos seus componentes lógicos" (2014, p. 262-263).
} 
num dos modais do dever-ser: $\mathrm{V}, \mathrm{P}$ ou $\mathrm{O}$, que são irredutíveis, mas interdefiníveis, isto é, com o auxílio do conectivo negador $(-)$, é dado definir um pelo outro ( $\mathrm{Op} \equiv-$ P-p) (2012, p. 46).

Da análise dos dizeres acima, extrai-se que o consequente de uma norma jurídica sempre se apresenta como uma proposição que estabelece uma relação jurídica entre determinados sujeitos unidos por um relacional deôntico.

Neste diapasão, o consequente da regra-matriz de incidência tributária elenca, além dos sujeitos desta relação na forma descrita acima, elementos estes tidos como o critério pessoal da norma, um critério quantitativo, que, por sua vez, expressa os fatores diretamente relacionados à quantificação do tributo:

Nele [no consequente da regra-matriz de incidência tributária] há feixes de informações que nos oferecem critérios de identificação dos elementos constitutivos do laço obrigacional: a) o critério pessoal, que aponta os sujeitos (ativo e passivo) da relação; e b) o critério quantitativo, indicador dos fatores que, conjugados, exprimem o valor pecuniário da dívida (base de cálculo e alíquota) (CARVALHO, 2014, p. 295).

Oportunamente, deve-se, sinteticamente, apresentar os componentes lógicos do consequente, dentre os quais se insere o elemento objeto do estudo de constitucionalidade proposto.

Assim, como visto, o consequente traz, como critérios identificativos dos elementos da relação obrigacional: o critério pessoal (que, por sua vez, subdivide-se em sujeito ativo e sujeito passivo) e o critério quantitativo (dividido ainda em base de cálculo e alíquota).

Adentrando na análise destes, o critério pessoal elenca os sujeitos do vínculo obrigacional, com os dados indicativos dos sujeitos ativo e passivo da relação jurídica tributária (CARVALHO, 2012). Nesta seara, o sujeito ativo é “(...) o titular do direito subjetivo de exigir a prestação pecuniária, no direito tributário brasileiro pode ser uma pessoa jurídica pública ou privada" (CARVALLHO, 2014, p. 296). O sujeito passivo, diferentemente, apresenta-se como:

(...) a pessoa — sujeito de direitos - física ou jurídica, privada ou pública, de quem se exige o cumprimento da prestação: pecuniária, nos nexos obrigacionais; e insuscetível de avaliação patrimonial, nas relações que veiculam meros deveres instrumentais ou formais (CARVALHO, 2014, p. 298).

Quanto ao critério quantitativo, afirma-se que este componente define o quantum da dívida tributária, sendo "o grupo de notícias informativas que o intérprete obtém da leitura atenta dos textos legais, e que lhe faz possível precisar, com segurança, a exata quantia devida 


\title{
A (IN)CONSTITUCIONALIDADE DA ALÍQUOTA NA REGRA-MATRIZ DE INCIDÊNCIA TRIBUTÁRIA DO ICMS SOBRE A CIRCULAÇÃO DE ENERGIA ELÉTRICA NO RICMS/ES
}

a título de tributo" (CARVALHO, 2014, p. 316). Tradicionalmente, este critério conjuga duas entidades: a base de cálculo e a alíquota.

A base de cálculo, na lição do Professor Paulo de Barros Carvalho, é:

\begin{abstract}
a grandeza instituída na consequência da regra-matriz tributária, e que se destina, primordialmente, a dimensionar a intensidade do comportamento inserto no núcleo do fato jurídico, para que, combinando-se à alíquota, seja determinado o valor da prestação pecuniária. Paralelamente, tem a virtude de confirmar, infirmar ou afirmar o critério material expresso na composição do suposto normativo. A versatilidade categorial desse instrumento jurídico se apresenta em três funções distintas: a) medir as proporções reais do fato; b) compor a específica determinação da dívida; e c) confirmar, infirmar ou afirmar o verdadeiro critério material da descrição contida no antecedente da norma (2014, p. 319).
\end{abstract}

A alíquota, por sua vez, em conjunto com a base de cálculo, define o valor objeto da relação jurídica tributária, possuindo, portanto, a função (principal, mas não a única) objetiva de definição do quantum debeatur, sendo submetida ao chamado regime da reserva legal (CARVALHO, 2014).

Assevera-se, ainda, por relevante, que, apesar de a doutrina tradicional não atribuir à alíquota função além da mera definição objetiva do valor da prestação pecuniária ${ }^{6}$, o referencial teórica aqui adotado, Paulo de Barros Carvalho, entende ser este componente verdadeiro concretizador de princípios constitucionais, como o princípio da isonomia tributária, considerando-o, também, o instrumento por meio do qual se implenta o caráter extrafiscal dos tributos:

É por mantê-la constante, sob a forma de fração, ou por fazê-la progredir, continuamente, ou por degraus, que o legislador busca realizar e assegurar o princípio da igualdade tributária. É também por contê-la dentro de certos limites que a autoridade legislativa evita que a tributação ganhe ares de confisco. Ao manipular os sistemas de alíquotas, implementa o político suas intenções extrafiscais e, por reduzi-las a zero (alíquota zero), realiza uma das modalidades de isenção (2014, p. 329).

Estabelecidas as premissas básicas para construção do raciocínio aprofundado adiante, sem mais delongas, passa-se à construção da regra-matriz de incidência objeto deste trabalho e à análise do seu componente lógico elencado para o estudo.

\footnotetext{
${ }^{6}$ Nos dizeres de Paulo de Barros Carvalho: "Realmente, se da análise da base de cálculo podemos recolher imenso material explicativo da fenomenologia impositiva, do exame da alíquota pouco mais se apanha que um componente aritmético para a determinação da quantia que será objeto da prestação tributária. Compagina-se à base de cálculo, na sua função eminentemente objetiva, como tivemos oportunidade de acentuar, e diríamos esgotar-se aí o interesse que pode suscitar, não exercesse a alíquota outro papel importantíssimo no que atina à própria legitimidade da imposição tributária" (2014, p. 327-328).
} 
Larissa Takla de Biase Nogueira

\section{A REGRA-MATRIZ DE INCIDÊNCIA TRIBUTÁRIA DO ICMS INCIDENTE SOBRE A CIRCULAÇÃO DE ENERGIA ELÉTRICA NO RICMS/ES}

Feitas estas digressões, pode-se então estabelecer a regra-matriz de incidência objeto desta análise pode ser assim estabelecida. ${ }^{7}$

Em primeiro lugar, no que tange à hipótese de incidência tributária, tem-se, como critério material, o ato de realizar operações de circulação da mercadoria energia elétrica, sendo os critérios espacial e temporal, respectivamente, os limites do Estado do Espírito Santo e o momento da transferência da titularidade do bem.

Em segundo lugar, no que diz respeito ao consequente da norma, observa-se, no critério pessoal, a presença do Estado do Espírito Santo (sujeito ativo) e do contribuinte que realizar a dita circulação (sujeito passivo). Por sua vez, no critério quantitativo, extrai-se, como base de cálculo, o valor do quantum do consumo da energia elétrica e, como alíquota, os percentuais de $25 \%$ ou $12 \% .^{8}$

Cumpre-se informar, neste momento, que uma análise ampla e irrestrita de cada um dos critérios vistos acima e seus desdobramentos sobre o imposto em questão possuiria o condão de permitir, a priori, a identificação de diversas inconstitucionalidades e/ou ilegalidades, além de inúmeras considerações de ordem teórica. No presente trabalho, todavia, optou-se pelo exame mais aprofundado de apenas um desses critérios, em que foi verificada grave violação a caros princípios constitucionalmente postos.

Desta feita, como já adiantado nas notas introdutórias, proceder-se-á a um corte metodológico da análise da constitucionalidade da regra-matriz de incidência tributária do ICMS no RICMS/ES de forma a delimitar o seu escopo apenas à alíquota, dentro do critério quantitativo em seu consequente.

\section{DOS PRINCÍPIOS CONSTITUCIONAIS EM MATÉRIA TRIBUTÁRIA COMO LIMITES À COMPETÊNCIA TRIBUTÁRIA DO LEGISLADOR ORDINÁRIO}

De forma anterior ao cotejo dos princípios constitucionais em análise neste artigo, é preciso que, inicialmente, se estabeleça, como premissa lógica, o papel de tais cânones em matéria tributária, particularmente no que tange à instituição da regra-matriz.

\footnotetext{
${ }^{7}$ Delimita-se a construção em questão apenas para a norma genérica, o suficiente para a análise em comento, sem abordar, entretanto, situações como substituições tributárias, diferimento, etc.

${ }^{8}$ A alíquota sofrerá variação nesta regra-matriz conforme a subclassificação constante do RICMS/ES, aspecto este que será melhor abordado adiante.
} 


\section{A (IN)CONSTITUCIONALIDADE DA ALÍQUOTA NA REGRA-MATRIZ DE INCIDÊNCIA TRIBUTÁRIA DO ICMS SOBRE A CIRCULAÇÃO DE ENERGIA ELÉTRICA NO RICMS/ES}

Neste ponto, defende-se que os princípios estabelecidos pela Constituição Federal funcionam como verdadeiros limites que devem ser necessariamente considerados como balizamento na instituição da regra-matriz de incidência tributária para que a norma seja válida perante o sistema jurídico em vigor

Justamente por isso, diz-se que o princípio constitucional em matéria tributária, via de regra, se caracteriza como uma norma jurídica de estrutura (norma jurídica primária) que obriga o legislador ordinário dos Estados e do Distrito Federal ao instituírem as suas respectivas regras-matrizes de incidência tributária do ICMS.

Sobre esta questão, traz-se à baila a lição de Tárek Moysés Moussallem:

É usual a distinção entre regra de estrutura e regra de comportamento. Norberto Bobbio, idealizador da classificação em tela, reconhece que o ordenamento, ao lado de regular o comportamento das pessoas, prescreve também o modo de produção normativa. Esta última é denominada norma de estrutura (normas para produção de outras normas) e aquelas, norma de conduta. (...) São tidas como normas de produção normativa aquelas que outorgam competência, que estabelecem procedimentos legislativos, administrativos e judiciais (...) (2005, p. 102).

Neste sentido, caso se verifique o descumprimento desta norma primária pelo legislador ordinário, isto é, caso a norma jurídica estabelecida pelo legislador esteja em desacordo com determinado princípio constitucional estabelecido como limite à sua competência tributária, surge ao contribuinte a possibilidade de suscitar, na via judicial, o controle da constitucionalidade deste ato, nos termos do artigo 97 da Constituição Federal ${ }^{9}$.

De fato, a posição que se defende não significa atribuir ao Poder Judiciário a atribuição de legislar, mas sim reconhecer a necessária possibilidade de intervenção deste poder no controle de atos legislativos atentatórios ao ordenamento jurídico, desde que respeitada a competência tributária do ente legislativo.

Em outras palavras, sendo o princípio constitucional em matéria tributária uma norma de estrutura que vincula diretamente o legislador ordinário na instituição do ICMS, pode o contribuinte valer-se da tutela jurisdicional para questionar o seu descumprimento, suscitando a veiculação de uma norma individual e concreta que disponha, tomando por exemplo o critério em apreço, a alíquota aplicável ao caso concreto, contando que sejam atendidos os limites, em termos percentuais, estabelecidos pela legislação estadual.

\footnotetext{
${ }^{9}$ Art. 97. Somente pelo voto da maioria absoluta de seus membros ou dos membros do respectivo órgão especial poderão os tribunais declarar a inconstitucionalidade de lei ou ato normativo do Poder Público (BRASIL, 1988).
} 
Defende-se, neste caso, que o judiciário estaria tão somente adequando a alíquota estabelecida no caso em questão a um patamar já existente na legislação ordinária, tendo como balizamento as alíquotas mínimas e máximas constantes do RICMS/ES.

\subsection{O PRINCÍPIO CONSTITUCIONAL DA SELETIVIDADE EM RAZÃO DA ESSENCIALIDADE DA MERCADORIA}

Como se sabe, a primordial função dos tributos é de abastecimento dos cofres públicos, constituindo a chamada receita derivada do Estado. Tais tributos possuem função eminentemente fiscal.

Há determinados tributos, entretanto, que não visam tão somente à arrecadação tributária, haja vista terem também um aspecto extrafiscal, voltado à regulação do mercado, à circulação desonerada de bens tidos como essenciais à população etc.

Neste sentido, Hugo de Brito Machado leciona:

(...) Assim, quanto a seu objetivo, o tributo é: a) Fiscal, quando seu principal objetivo é a arrecadação de recursos financeiros para o Estado; b) Extrafiscal, quando o seu objetivo é a interferência no domínio econômico, buscando um efeito diverso da simples arrecadação de recursos financeiros (2003, p.68).

A partir da Constituição Federal de 1988, o ICMS é considerado um tributo de caráter fiscal e extrafiscal, este último em razão da sua função de facilitar a circulação de mercadorias essenciais ao consumo humano. Nestes termos, o ICMS, ao se constituir também como um instrumento extrafiscal, deve onerar as operações com mercadorias e prestação de serviços de maneira inversamente proporcional à sua essencialidade, em atendimento ao princípio constitucional da seletividade pela essencialidade, disposto no artigo $155, \S 2^{\circ}$, inciso III, da Constituição Federal. ${ }^{10}$

Neste ponto, deve-se realizar um adendo para ressaltar que, apesar de a Constituição Federal ter utilizado o termo "poder", este deve ser entendimento como um "dever". Isto porque, ao estabelecer normas de direito tributário, a Constituição não propõe meras recomendações aos entes tributários, mas sim determina regras que devem necessariamente

\footnotetext{
${ }^{10}$ Artigo 155. Compete aos Estados e ao Distrito Federal instituir impostos sobre: (Redação dada pela Emenda Constitucional $n^{\circ}$ 3, de 1993) (...) II - operações relativas à circulação de mercadorias e sobre prestações de serviços de transporte interestadual e intermunicipal e de comunicação, ainda que as operações e as prestações se iniciem no exterior; (Redação dada pela Emenda Constitucional no 3, de 1993) (...) § 2. ${ }^{\circ}$ O imposto previsto no inciso II atenderá ao seguinte: (Redação dada pela Emenda Constitucional no 3, de 1993) (...) III - poderá ser seletivo, em função da essencialidade das mercadorias e dos serviços (BRASIL, 1988).
} 


\title{
A (IN)CONSTITUCIONALIDADE DA ALÍQUOTA NA REGRA-MATRIZ DE INCIDÊNCIA TRIBUTÁRIA DO ICMS SOBRE A CIRCULAÇÃO DE ENERGIA ELÉTRICA NO RICMS/ES
}

ser seguidas. ${ }^{11}$ Segundo tal princípio, portanto, quanto mais essenciais as mercadorias sejam à sociedade, menor deve ser a respectiva tributação.

No tocante ao ICMS em particular, calha ainda ressaltar que este princípio constitucional está voltado primordialmente à constatação da imprescindibilidade da mercadoria e/ou prestação de serviços, sendo irrelevantes, neste caso, quaisquer outros critérios extrínsecos à operação, a exemplo da capacidade econômica dos contratantes.

Confira-se novamente, nesta acepção, a doutrina de Roque Antonio Carrazza:

(...) Cumpre-se o princípio da seletividade comparando-se mercadorias ou serviços. Nunca, evidentemente, discriminando-se contribuintes, em função de raça, sexo, ocupação profissional etc., que a isto obsta o artigo $5^{\circ}$, I, da CF. As mercadorias de primeira necessidade devem, necessariamente, ser menos onerados, por via de ICMS, que os supérfluos ou suntuários (2005, p. 361).

Estabelecidas tais premissas, será demonstrado, a seguir, que, apesar de o legislador ordinário ter se atentado ao preceito constitucional da seletividade na instituição do ICMS em relação a algumas mercadorias e serviços, este não foi o caso no concernente à energia elétrica.

\subsection{O PRINCÍPIO CONSTITUCIONAL DA ISONOMIA TRIBUTÁRIA}

Além do princípio tratado anteriormente, outro princípio constitucional deve ser analisado para realização do estudo que se propõe. Trata-se do princípio constitucional da isonomia tributária, previsto no artigo 150, inciso II, da Constituição Federal:

\begin{abstract}
Art. 150. Sem prejuízo de outras garantias asseguradas ao contribuinte, é vedado à União, aos Estados, ao Distrito Federal e aos Municípios: (...) II - instituir tratamento desigual entre contribuintes que se encontrem em situação equivalente, proibida qualquer distinção em razão de ocupação profissional ou função por eles exercida, independentemente da denominação jurídica dos rendimentos, títulos ou direitos (BRASIL, 1988).
\end{abstract}

Nos dizeres de Leandro Paulsen, "A isonomia imposta pelo art. 150, II, da CF impede que haja diferenciação tributária entre contribuintes que estejam em situação equivalente, ou seja, veda a discriminação arbitrária” (2014, p. 81).

Ainda, segundo Paulo de Barros Carvalho, “(...) a isonomia opera justamente nessas situações, acionando a proporcionalidade e, com isso, temperando as desigualdades jurídicas

\footnotetext{
${ }^{11}$ Confira-se, neste pormenor, as palavras de Roque Antonio Carrazza: (...) Convém salientarmos, desde logo, que, a nosso ver, este singelo "poderá" equivale, na verdade, a um peremptório "deverá". Não está, aí, diante de uma mera faculdade do legislador, mas de uma norma cogente, de observância obrigatória. Ademais, quando a Constituição confere a uma pessoa política um "poder", ela, ipso facto, lhe impõe um "dever". É por isso que se costuma falar que as pessoas políticas têm poderes deveres (2005, p. 361).
} 
entre os sujeitos de direito" (2014, p. 514), motivo pelo qual seria considerado um “sobreprincípio" (CARVALHO, [s.d.]).

Neste diapasão, observa-se que o princípio constitucional da isonomia tributária deve ser observado pelo legislador ordinário no exercício da competência tributária, apenas se justificando a diferenciação no tratamento de diferentes contribuintes quando, embasado em razões extrafiscais ${ }^{12}$, seja estabelecido um critério que guarde relação com a finalidade pretendida e que tal critério seja efetivamente capaz de atingir tal fim (PAULSEN, 2014).

Assim, na linha do exposado, Sabbag critica a possibilidade de adoção de critérios que, em tese, legitimiriam o estabelecimento de diferenças na mitigação deste postulado:

\begin{abstract}
Nesse passo, diz-se que o princípio da isonomia tributária é postulado vazio, recebendo o conteúdo axiológico de outros valores, como a liberdade e a justiça, ou, "justiça tributária", na expressão utilizada pelo STF (RE 423.768, rel. Min. Marco Aurélio, Pleno, j. em $1^{\circ}$-12-2010). Daí se notar o previsível elemento desafiador ao exegeta que se põe diante do intrincado tema da interpretação do postulado da isonomia tributária: indagar -se sobre a legitimidade dos critérios distintivos adotados na atividade de desigualização, além da simples valoração, em si, dos critérios adotados (2017, p. 173).
\end{abstract}

Oportunamente, deve-se salientar que, nos mesmos termos defendidos no item pretérito deste trabalho, o desrespeito a este princípio também pode ser objeto de demanda judicial. Apesar de este caso ainda motivar certo debate, tendo em vista o anterior posicionamento desfavorável dos tribunais, constata-se que, atualmente, é reconhecida a possibilidade de questionamento na via judicial. Confira-se a este teor:

$\mathrm{O}$ argumento de que o Judiciário não pode atuar como legislador positivo muitas vezes fundamentou a improcedência de ações em que o autor apontava violação à isonomia pleiteando a extensão de tratamento privilegiado concedido por lei a outrem. Com isso, o Judiciário acabou por deixar de oferecer prestação jurisdicional que assegurasse tratamento isonômico, razão pela qual tem sido cada vez mais criticada tal posição, havendo quem diga que "equivale a eliminar o princípio da igualdade". Tem-se defendido, pois, mais recentemente, que o Judiciário "pode declarar a nulidade do critério de diferenciação violador do princípio da igualdade, de modo a que todas as pessoas e grupos possam ser incluídas" (...) (PAULSEN, 2014, p. 83).

É importante, entretanto, efetuar a mesma ressalva feita anteriormente: o Poder Judiciário deve tão somente adequar a alíquota atentando-se para os percentuais já pré-

\footnotetext{
${ }^{12} \mathrm{O}$ autor Hugo de Brito Machado Segundo faz a seguinte reflexão sobre o tema: "Há quem diga que, em matéria tributária, isonomia e capacidade contributiva são a mesma coisa, pois o critério para aferir se dois contribuintes estão ou não estão em situação equivalente (tratar desigualmente os desiguais na medida em que se desigualam) seria exatamente a capacidade contributiva. Não é bem assim, contudo. Em algumas situações, nas quais se estiver utilizando o tributo para atingir finalidades extrafiscais, outras medidas de desigualdade podem ser consideradas" (2017, p. 47).
}

Revista de Direito Tributário e Financeiro | e-ISSN: 2526-0138 | Porto Alegre | v. 4 | n. 2 | p. 01 - 22 Jul/Dez. 2018 
estabalecidos pelo ente legislativo estadual, sob pena de usurpação da competência tributária deste.

Estabelecidas tais premissas, passa-se então à análise da constitucionalidade da regra-matriz do ICMS incidente sobre o fornecimento de energia elétrica no âmbito do RICMS/ES sob a ótica também deste princípio constitucional.

\section{A INCONSTITUCIONALIDADE DA ALÍQUOTA DE 25\% PARA O ICMS} INCIDENTE SOBRE A CIRCULAÇÃO DE ENERGIA ELÉTRICA FRENTE À ESSENCIALIDADE DO FORNECIMENTO DE ENERGIA ELÉTRICA E AO FERIMENTO À ISONOMIA DOS CONSUMIDORES DESTE BEM

É inconteste que, na sociedade atual, a energia elétrica é um bem primordial, sem o qual todas as atividades agrícolas, industriais e comerciais, bem como, por consequência, a própria vida humana, restariam comprometidas.

Destaca-se, neste ponto, que, hodiernamente, não são tidos como essenciais tão somente os bens diretamente ligados à satisfação das necessidades biológicas dos contribuintes, haja vista que tal conceito também engloba aquelas mercadorias das quais dependem a sociedade para seu funcionamento e para a manutenção de um padrão de vida adequado às necessidades mínimas do ser humano.

É este o entendimento do doutrinador Henry Tilbery:

O conceito de 'essencialidade' não deve ser interpretado estritamente para cobrir apenas as necessidades biológicas (alimentação, vestuário, moradia, tratamento médico), mas deve abranger também aquelas necessidades que sejam pressupostos de um padrão de vida mínimo decente, de acordo com o conceito vigente da maioria (1990, n. p.)

Neste sentido, é impensável a manutenção da complexa sociedade brasileira sem o fornecimento universal da energia elétrica. Isto porque a definição do que se constitui como um mínimo existencial para a vida digna, na acepção do princípio da dignidade humana, deve ser balizado dentro do contexto histórico e das demandas sociais da época, considerando-se, para tanto, o atual patamar de evolução tecnológica e social, que torna inimaginável a existência humana desassociada do fornecimento de energia elétrica.

$\mathrm{O}$ acesso ao fornecimento desta mercadoria, portanto, não pode mais ser desvinculado da manutenção da vida em uma comunidade interligada e interdependente, agregando-se à noção de mínimo existencial à existência digna. 
Ademais, toda a cadeia de abastecimento de produtos e serviços imprescindíveis à vida humana depende diretamente da transmissão de energia elétrica para se manter.

Diz-se, por isso, que o fornecimento de energia elétrica está intimamente ligado ao exercício de diversos direitos fundamentais constitucionalmente estabelecidos, dentre os quais se incluem a liberdade, a segurança, o bem-estar, o desenvolvimento, a igualdade e a justiça.

Tanto é que não são poucos os estudiosos do tema a defender a inclusão do acesso à energia elétrica como uma garantia fundamental constitucionalmente estabelecida por autorização da cláusula aberta trazida pelo artigo $5^{\circ}, \S 2^{\circ}$, da Constituição Federal ${ }^{13}$. Confira$\operatorname{se}^{14}$ :

(...) é por meio da cláusula aberta que podemos justificar a caracterização de direito fundamental ao acesso à energia elétrica, que seria decorrente tanto dos princípios do direito brasileiro (princípio da dignidade da pessoa humana, em especial), quanto do regime de Estado social democrático, adotado pelo legislador constituinte. (...) É diante dessa conjuntura narrada que surge a necessidade de se incluir o acesso à energia elétrica como um direito a ser assegurado para a manutenção de uma vida digna. Pois tal direito (acesso à energia elétrica) é de vinculação direta com a concretização de outros direitos fundamentais já positivados (vida digna, saúde, educação e outros), constituindo-se, desse modo, em parte integrante de um mínimo existencial para a efetivação da vida digna. (...) Desse modo, diante da realidade brasileira que assegura como básicos e fundamentais direitos como vida, saúde, educação, lazer, dignidade e exercício de cidadania, não é de difícil constatação que o acesso à energia elétrica seja básico também para a garantia desses direitos (ROSA, 2016, p. 12-20).

A partir de tais excertos, conclui-se que o fornecimento de energia elétrica também se revela como um direito fundamental, por ser um bem jurídico que se afigura como indispensável à manutenção e ao desenvolvimento da dignidade da pessoa humana, nos termos do artigo $1^{\circ}$, iniciso III, da Constituição Federal ${ }^{15}$.

\footnotetext{
${ }^{13}$ Art. $5^{\circ}$ Todos são iguais perante a lei, sem distinção de qualquer natureza, garantindo-se aos brasileiros e aos estrangeiros residentes no País a inviolabilidade do direito à vida, à liberdade, à igualdade, à segurança e à propriedade, nos termos seguintes: (...) $\S 2^{\circ}$ Os direitos e garantias expressos nesta Constituição não excluem outros decorrentes do regime e dos princípios por ela adotados, ou dos tratados internacionais em que a República Federativa do Brasil seja parte (BRASIL, 1988).

${ }^{14}$ No mesmo sentido: (...) a distribuição de energia elétrica constitui-se em atividade essencial para o mundo moderno, assumindo simultaneamente dois papéis: causa e consequência do desenvolvimento das sociedades. (...) $\mathrm{O}$ acesso à energia elétrica, em adição, vincula-se também à concretização de direitos fundamentais variados, permitindo aos indivíduos o exercício de uma vida mais digna. Diante disso, pode-se asseverar que a liberdade de escolha alcançada mediante o acesso amplo à energia permite que os indivíduos busquem a concretização da sua da dignidade e do desenvolvimento. (...) Desse modo, o acesso à energia vincula-se à liberdade, ao desenvolvimento, à dignidade e à concretização de diversos direitos fundamentais, sendo dever do ente estatal nacional promover o bem de todos, incluindo-se aí o próprio acesso universal à energia elétrica no país (CAVALCANTE, 2013, 63-64).

${ }^{15}$ Art. $1^{\circ}$ A República Federativa do Brasil, formada pela união indissolúvel dos Estados e Municípios e do Distrito Federal, constitui-se em Estado Democrático de Direito e tem como fundamentos: (...) III - a dignidade da pessoa humana (BRASIL, 1988).
}

Revista de Direito Tributário e Financeiro | e-ISSN: 2526-0138 | Porto Alegre | v. 4 | n. 2 | p. 01 - 22 Jul/Dez. 2018 


\section{A (IN)CONSTITUCIONALIDADE DA ALÍQUOTA NA REGRA-MATRIZ DE INCIDÊNCIA TRIBUTÁRIA DO ICMS SOBRE A CIRCULAÇÃO DE ENERGIA ELÉTRICA NO RICMS/ES}

Feitas tais observações, insta salientar que o próprio legislador ordinário federal já reconheceu a imprescindibilidade do fornecimento de energia elétrica, alçando-o expressamente ao patamar de "serviço ou atividade essencial" por meio do artigo 10, inciso I, da Lei $\mathrm{n}^{\mathrm{o}} 7.783 / 89^{16}$.

Ademais, tal é a importância do fornecimento de energia elétrica que o Superior Tribunal de Justiça tem reconhecido, reiteradamente, a impossibilidade de suspensão no fornecimento deste bem mesmo diante do inadimplemento do consumidor e da fraude em medidores de consumo. Nos julgados que versam sobre este tema, esta corte sempre se pronuncia no sentido de reconhecimento da essencialidade do serviço de fornecimento de energia elétrica e da indispensabilidade desta mercadoria à vida humana ${ }^{17}$.

A essencialidade da energia elétrica também já é há muito reconhecida pelo Estado. Em 2003, foi instituído o Programa Nacional de Universalização do Acesso e Uso da Energia Elétrica, também conhecido como "Luz Para Todos", por meio do Decreto n 4.873, de 11 de novembro de 2003. O programa possuía como finalidade fornecer energia elétrica à população da zona rural brasileira que ainda não tinha acesso a esse bem fundamental, em um claro reconhecimento da necessidade de acesso universal às redes de energia elétrica para o desenvolvimento humano.

É inegável, portanto, a essencialidade da energia elétrica. Não obstante isto, a tributação atual desta mercadoria no Estado do Espírito Santo não se amolda à imprescindibilidade deste bem.

De acordo com o artigo 71 do RICMS/ES, a alíquota aplicável no caso do ICMS incidente sobre a circulação de energia elétrica, no caso das autoras, é atualmente de $25 \%$. Confira-se:

\footnotetext{
${ }^{16}$ Art. 10 São considerados serviços ou atividades essenciais: I - tratamento e abastecimento de água; produção e distribuição de energia elétrica, gás e combustíveis; (...) (BRASIL, 1989).

${ }^{17}$ Confira-se alguns exemplos: [...] 2. "A concessionária não pode interromper o fornecimento de energia elétrica por dívida relativa à recuperação de consumo não-faturado, apurada a partir da constatação de fraude no medidor, em face da essencialidade do serviço, posto bem indispensável à vida" (AgRg no REsp 854.002/RS, $1^{\mathrm{a}}$ Turma, Rel. Min. Luiz Fux, DJ de 11.6.2007). [...]. (AGA 201001136906, MAURO CAMPBELL MARQUES, STJ - SEGUNDA TURMA, DJE DATA:25/11/2010 ..DTPB:); [...] 1. A "concessionária não pode interromper o fornecimento de energia elétrica por dívida relativa à recuperação de consumo não-faturado, apurada a partir da constatação de fraude no medidor, em face da essencialidade do serviço, posto bem indispensável à vida. Entendimento assentado pela Primeira Turma, no julgamento do REsp n. $.^{\circ} 772.489 / \mathrm{RS}$, bem como no AgRg no AG 633.173/RS" (AgRg no REsp 854002/RS, $1^{\text {a }}$ Turma, Min. Luiz Fux, DJ de 11.06.2007). 2. Recurso especial a que se nega provimento. (REsp 819.004/RS, Rel. Ministro TEORI ALBINO ZAVASCKI, PRIMEIRA TURMA, julgado em 04/03/2008, DJe 17/03/2008).
} 
Art. 71. As alíquotas do imposto são: II - doze por cento: c) no fornecimento de energia elétrica, consumida exclusivamente na produção agrícola, inclusive de irrigação; d) no fornecimento de energia elétrica para consumidores de até cinqüienta quilowatts-hora/mês; (...) III - vinte e cinco por cento, nas operações internas com energia elétrica, salvo o disposto no inciso II, c e d (ESPÍRITO SANTO, 2002).

Percebe-se da redação do artigo alhures que o princípio da seletividade não foi observado pelo legislador ordinário na instituição desta regra, visto ter este eleito a alíquota de $25 \%$ para o fornecimento de energia elétrica no caso nas operações internas com energia elétrica como regra geral.

Deve-se ressaltar, neste sentido, que este patamar de alíquota de ICMS em que o fornecimento de energia elétrica atualmente se encaixa é o mesmo de outras mercadorias e serviços que não se coadunam, ou sequer se aproximam, do seu nível de essencialidade.

Da análise detida do artigo 71 do RICMS/ES, percebe-se que os seguintes produtos também foram classificados no percentual de $25 \%$ de alíquota de ICMS: armas e munições, suas partes e acessórios; bebidas alcoólicas; fumo e seus sucedâneos manufaturados; jóias e bijuterias; perfumes e cosméticos; jogos eletrônicos de vídeo; confete e serpentinas; etc. ${ }^{18}$

Evidentemente, se o princípio da seletividade deve ser obrigatoriamente observado pelo legislador ao encaixar determinada mercadoria ou prestação de serviço em uma dada alíquota na regra-matriz do ICMS, estar-se-ia admitindo que a energia elétrica se encontra no mesmo patamar de essencialidade para a manutenção e desenvolvimento da vida humana que as armas, os cigarros, as bebidas alcoólicas, as jóias e acessórios, os perfumes e cosméticos, dentre outros.

Assim, é imperioso reconhecer que apenas o fato de tais mercadorias estarem no mesmo patamar de alíquota que a energia elétrica é indicativo mais que suficiente, por si só, de que o legislador ordinário não atendeu ao princípio da seletividade em razão da essencialidade ao estipular a alíquota incidente sobre a mercadoria ora discutida.

Isto fica ainda mais evidente quando verificada a atribuição, pelo RICMS/ES, de alíquota consideravelmente inferior a mercadorias menos essenciais às atividades industriais,

\footnotetext{
${ }^{18}$ Art. 71. As alíquotas do imposto são: (...) IV - vinte e cinco por cento, nas prestações de serviço de comunicação realizadas no território deste Estado e nas operações internas, inclusive de importação, realizadas com bens e mercadorias a seguir indicados, classificados segundo os respectivos códigos da NBM/SH: (...) b) armas e munições, suas partes e acessórios - capítulo 93; (...) d) bebidas alcoólicas - posições 2203 a 2206, 2207.20 e 2208; e) fumo e seus sucedâneos manufaturados - capítulo 24; f) jóias e bijuterias - posições 7113, 7114, 7116 e 7117; g) perfumes e cosméticos - posições 3303, 3304, 3305 e 3307; (...) n) jogos eletrônicos de vídeo (vídeo-jogo) - 9504.10.0100; (...) q) confete e serpentinas - 9505.90.010 (ESPÍRITO SANTO, 2002).
} 


\section{A (IN)CONSTITUCIONALIDADE DA ALÍQUOTA NA REGRA-MATRIZ DE INCIDÊNCIA TRIBUTÁRIA DO ICMS SOBRE A CIRCULAÇÃO DE ENERGIA ELÉTRICA NO RICMS/ES}

comerciais e agrícolas e à manutenção da sociedade como um todo. Tome-se como exemplo o caso previsto na alínea "l" do inciso II deste dispositivo ${ }^{19}$, que estabelece a alíquota de $12 \%$ para as operações com os produtos classificados no NCM/SH 8903.92.00 e 8903.99.00, isto é, barcos à vela, mesmo com motor auxiliar e barcos a motor, exceto com motor fora-de-borda. ${ }^{20}$

Voltando-se à análise da alíquota incidente sobre o bem em questão, outro problema exsurge do estabelecimento do percentual de $25 \%$ como regra geral para a regra-matriz em comento.

Isto porque, curiosamente, a alíquota utilizada em regra-matriz quase idêntica, com diferenciação apenas quanto ao seu critério pessoal, recebeu tratamento completamente diverso. Conforme se observa das alíneas "c" e "d" do inciso II do dispositivo acima transcrito, a alíquota estabelecida para o fornecimento de energia elétrica consumida na produção agrícola ou destinada a consumidores de até 50 quilowatts-hora/mês é de $12 \%$.

Nestes dois casos, percebe-se que o legislador ordinário se atentou à essencialidade da energia elétrica, em respeito ao princípio constitucional da seletividade, utilizando uma alíquota bem menos onerosa dada a importância deste bem.

Tal contradição, contudo, se revela absolutamente inconstitucional. Como cediço, a energia elétrica é sempre essencial independentemente do seu consumo ou do setor ao qual está sendo destinada. Incontestavelmente, o contribuinte pessoa física, bem como uma indústria ou comércio necessitam tanto do fornecimento de energia elétrica quanto a produção agrícola. É impossível se pensar, a título demonstrativo, em uma empresa funcionando sem o abastecimento de energia elétrica.

E não se diga que o setor agrícola, por exemplo, é mais essencial que o setor comercial, haja vista a produção de alimentos estar diretamente vinculada àquele em detrimento deste, pois tais conjecturas são de completa irrelevância para o tema em questão. Conforme já estabelecido em tópico anterior, o foco do princípio constitucional da seletividade está voltado à essencialidade da mercadoria, e não do contribuinte a que a mercadoria será destinada.

\footnotetext{
${ }^{19}$ Art. 71. As alíquotas do imposto são: (...) II - doze por cento (...) 1) nas operações internas com os produtos classificados nos códigos NCM/SH 8903.92.00 e 8903.99.00; (...).

20 Classificação retirada da tabela fornecida pela Receita Federal. Disponível em: <http://www4.receita.fazenda.gov.br/simulador/PesquisarNCM.jsp?codigo=89039\&codigoCapitulo=89\&codigo Posicao=8903\&codigoSubPosicao1=89039> . Acesso em: 27. nov. 2017.
} 
Não pode o legislador ordinário, por conseguinte, reconhecer a essencialidade da energia elétrica e utilizar a alíquota de $12 \%$ na regra matriz do ICMS para esta mercadoria em uma determinada situação e adotar a alíquota de $25 \%$ para a mesma mercadoria em outra situação. Trata-se do mesmo bem, igualmente essencial a qualquer contribuinte que dele usufrua.

Ademais, ao estabelecer, concomitantemente, as alíquotas de 12\% de ICMS incidente sobre a circulação de energia elétrica nestas situações e de $25 \%$ como regra geral, o legislador ordinário viola ainda o princípio constitucional da isonomia tributária, uma dos mais importes princípios da Carta Magna, conforme exposto no tópico anterior.

Oportunamente, esclarece-se que não se está diante de critério legítimo para a relatada diferenciação de tratamento, tendo em vista que, nos moldes da fundamentação supra, a nítida essencialidade da mercadoria energia elétrica sobrepõe-se a critérios ligados ao poder econômico do contribuinte ou à atividade em que este bem estaria sendo empregado. Nesta toada, percebe-se que, especialmente ao se confrontar a alínea "c" do inciso II do artigo 71, do RICMS/ES, com o inciso III deste mesmo artigo, o que legislador fez foi justamente estabelecer tratamento diverso a contribuinte em função meramente de ocupação profissional, incorrendo em grave violação ao princípio constitucional da isonomia tributária.

Assim, apesar de correta a tratativa do legislador em relação às situações previstas nas alíneas "c" e "d" do inciso II do artigo 71 do RICMS/ES, haja vista o estabelecimento de alíquota reduzida a um bem essencial, a alíquota fixada pelo inciso III do mesmo dispositivo não está de acordo com a disciplina constitucional do tema, violando os princípios da seletividade e da isonomia tributária.

Por tal motivo, defende-se o direito do contribuinte de, por meio da proposição de demanda judicial, obter provimento jurisdicional declarando a inconstitucionalidade da alíquota no âmbito da regra-matriz de incidência tributária do ICMS incidente sobre a circulação de energia elétrica no RICMS/ES.

De fato, não se pode admitir que o Poder Judiciário compactue com a norma jurídica em questão, o que significaria, em última análise, permitir e perpetrar gravíssima ofensa à Constituição Federal. 


\section{A (IN)CONSTITUCIONALIDADE DA ALÍQUOTA NA REGRA-MATRIZ DE INCIDÊNCIA TRIBUTÁRIA DO ICMS SOBRE A CIRCULAÇÃO DE ENERGIA ELÉTRICA NO RICMS/ES}

Neste sentido, ressalta-se que o Supremo Tribunal Federal já reconheceu, em julgamento realizado em 12/06/2014, a repercussão geral deste tema ${ }^{21}$. Ressalta-se que, muito embora a legislação específica do caso em análise seja a constante do Regulamento do ICMS do Estado de Santa Catarina, o percentual adotado foi idêntico ao estabelecido no RICMS/ES e a admissão da repercussão se deu justamente com base na reiteração de normas semelhantes em diversos membros da federação.

Apesar de ainda não haver sido proferida a decisão final quanto a este Recurso Extraordinário, a Corte Suprema já sinalizou entendimento, em outra oportunidade ${ }^{22}$, acerca da inconstitucionalidade da fixação da alíquota de $25 \%$ para o ICMS incidente sobre a mercadoria energia elétrica, por ofensa ao princípio da seletividade.

Além disso, o próprio Procurador Geral da República, Rodrigo Janot Monteiro de Barros, instado a se manifestar no Recurso Extraordinário acima mencionado, não só se posicionou no sentido de reconhecimento da violação ao princípio constitucional da seletividade neste caso, como, ainda, suscitou a necessidade de controle judicial desta grave ofensa à Carta Magna. ${ }^{23}$

Em referência ao já sinalizado entendimento da Corte Suprema, também a jurisprudência dos tribunais de justiça do país tem se manifestado de forma favorável à tese defendida neste $\operatorname{artigo~}^{24}$, o que demonstra a maturidade do Poder Judiciário na efetivação das

\footnotetext{
${ }^{21}$ RE 714139 SC, Relator(a): Min. MARCO AURÉLIO, julgado em 12/06/2014, PROCESSO ELETRÔNICO DJe-188 DIVULG 25-09-2014 PUBLIC 26-09-2014.

${ }^{22}$ Posicionamento adotado no RE 634457 AgR / RJ - RIO DE JANEIRO. AG. REG. NO RECURSO EXTRAORDINÁRIO. Relator (a): Min. RICARDO LEWANDOWSKI. Julgamento: 05/08/2014.

${ }^{23}$ Tem o ICMS, na sua atual conformação constitucional, não só a função de arrecadar receitas para Estados e Distrito Federal, mas também de facilitar a circulação de mercadorias e a prestação de serviços essenciais, de um lado, e de desestimular a de supérfluos e produtos prejudiciais à saúde da população, de outro. Segundo o magistério de Roque Antônio Carraza, a seletividade do ICMS pode ser alcançada por mais de uma técnica, como é o caso da criação de alíquotas diferenciadas, da variação de bases de cálculo e da criação de incentivos fiscais. Contudo, é na esfera da variação de alíquotas que a seletividade se faz mais facilmente alcançável. (...) O legislador estadual, abraçando a seletividade, discriminou, no entanto, alíquota especial superior, no patamar de $25 \%$ (vinte e cinco por cento), para operações com energia elétrica, produtos supérfluos, gasolina automotiva, álcool carburante e prestação de serviços de comunicação. (...) Observa-se, de plano, a desproporcionalidade entre a alíquota geral e a aplicada à energia elétrica e aos serviços de telecomunicação. Esse contraste é ainda mais nítido quando se tem em mente que a mesma alíquota incidente sobre produtos supérfluos é destinada à energia e às telecomunicações, essenciais ao exercício da dignidade humana. (...) Por outro lado, ao tributar sobremaneira o consumidor comum de energia e serviços de telecomunicação, o legislador estadual criou fator de discrímen que malfere o direito do contribuinte à facilitação do acesso a esses produtos/serviços. O Poder Judiciário tem não apenas a competência, mas igualmente o dever de investigar a questão (CF, art. $\left.5^{\circ}, \mathrm{XXXV}\right)$, de modo a afastar do cenário jurídico a lei inconciliável com a proteção constitucional ao contribuinte (BRASIL, 2015).

${ }^{24}$ Cita-se, nesse sentido, a decisão proferida no seguinte acórdão: TJ-CE; APL 03986822320108060001 CE 0398682-23.2010.8.06.0001; 8a Câmara Cível; Publicação16/02/2016.
} 
normas constitucionais e o reconhecimento das garantias do contribuinte frente à instituição de normas violadoras de tais ditames, especialmente em se tratando das regras da competência esparsa dos entes estaduais.

Ante todo o exposto, sustenta-se a inconstitucionalidade da alíquota da regra-matriz de incidência tributária do ICMS incidente sobre o fornecimento de energia elétrica estabelecida no artigo 71, inciso III, do RICMS/ES, devendo esta ser reduzida, por meio de alteração legislativa, preferencialmente, ou por meio da propositura de demandas ao Poder Judiciário, ao patamar de $12 \%$, em atendimento aos princípios constitucionais da seletividade em razão da essencialidade desta mercadoria e da isonomia tributária dos consumidores deste bem.

\section{CONSIDERAÇÕES FINAIS}

O presente estudo foi realizado para os fins de exame da constitucionalidade da alíquota na regra-matriz de incidência tributária do ICMS incidente sobre a circulação de energia elétrica no âmbito do RICMS/ES.

Neste panorama, analisou-se, no primeiro capítulo, a estrutura e os componentes lógicos da regra-matriz, de forma a definir e delimitar o objeto do exame proposto, bem como estabelecer a sua importância e relação com os demais critérios. No capítulo subsequente, adentrou-se no estudo dos princípios constitucionais da seletividade pela essencialidade do bem e da isonomia tributária, verificando-se, no tópico final, a adequação da referida alíquota a estes cânones da Carta Magna.

Foi denotado, no decorrer do trabalho, que o legislador ordinário estadual não se atentou ao regramento principiológico pertinente ao tema na determinação deste critério quantitativo, eis que estabeleceu uma alíquota majorada (25\%) para um produto essencial ao desenvolvimento humano no atual contexto de uma sociedade inegavelmente interdependente da tecnologia e da eletricidade. Além disso, a fixação de alíquota em menor percentual (12\%) a determinados contribuintes constitui-se em claro tratamento desigual sem a existência de um critério que legitimasse tal diferenciação.

Por todo o exposto, conclui-se, ao final do estudo, pela inconstitucionalidade da alíquota geral de $25 \%$ na regra-matriz de incidência tributária do ICMS incidente sobre a circulação de energia elétrica no contexto do RICMS/ES, ante a violação dos princípios da seletividade e da isonomia tributária, sendo necessária a alteração legislativa para diminuição 


\section{A (IN)CONSTITUCIONALIDADE DA ALÍQUOTA NA REGRA-MATRIZ DE INCIDÊNCIA TRIBUTÁRIA DO ICMS SOBRE A CIRCULAÇÃO DE ENERGIA ELÉTRICA \\ NO RICMS/ES}

deste percentual ou, alternativamente, a proposição de demandas judiciais que questionem a constitucionalidade deste critério ante a inobservância dos limites à competência tributária estabelecidos na Carta Magna.

\section{REFERÊNCIAS}

BRASIL. Constituição da República Federativa do Brasil de 1988. Disponível em: <https://www.planalto.gov.br/>. Acesso em: 15 out. 2017.

Decreto $n^{\circ} 4.873$, de 11 de novembro de 2003. Disponível em:

<https://www.planalto.gov.br/>. Acesso em: 21 out. 2017.

Lei $n^{\circ} 7.783$, de 28 de junho de 1989. Disponível em:

<https://www.planalto.gov.br/>. Acesso em: 18 out. 2017.

Lei $n^{\circ} 7.783$, de 28 de junho de 1989. Disponível em

<http://www.planalto.gov.br/ccivil_03/LEIS/L7783.htm>. Acesso em 4 set. 2018.

Procuradoria-Geral da República, Parecer $\mathrm{n}^{\circ}$ 1106/2015 - ASJCIV/SAJ/PGR ao RE $\mathrm{n}^{\mathrm{o}}$ 714139/SC, Rodrigo Janot Monteiro de Barros, 2015.

. Superior Tribunal de Justiça, AG nº 201001136906, Rel. Min. Marco Campbell Marques, 2010.

, REsp nº 819.004/RS, Rel. Min. Teori Albino Zavascki, 2008.

. Supremo Tribunal Federal, RE nº 634457/RJ, Rel. Min. Ricardo Lewandowski, 2014. , RE ñ 714139/SC, Rel. Min. Marco Aurélio, 2014.

CEARÁ. Tribunal de Justiça. AC nº 03986822320108060001, Rel. Des. Francisco Darival Beserra Primo, 2016.

CARRAZZA, Roque Antonio. ICMS. 10. ed. São Paulo: Malheiros Editores. 2005.

CAVALCANTE, Hellen Priscilla Marinho. O acesso à energia elétrica no Brasil sob a ótica do desenvolvimento à liberdade. Rev. Direito Econ. Socioambiental. Curitiba, v. 4, n. 2, p. 5886, jul./dez. 2013. Disponível em: <www2.pucpr.br/>. Acesso em: 17 fev. 2017.

CARVAlHO, Aurora Tomazini de. Curso de Teoria Geral do Direito. São Paulo: Noeses, 2009.

CARVALHO, Paulo de Barros. Curso de Direito Tributário. 26. ed. São Paulo: Saraiva, 2014. 
Direito tributário: fundamentos jurídicos da incidência. 9. ed. rev. São Paulo:

Saraiva, 2012.

Direito tributário: linguagem e método. 6. ed. São Paulo: Noeses, 2015.

O princípio da anterioridade em matéria tributária. Revista de Direito Tributário. São

Paulo: Malheiros, n. 63, [s.d.].

Teoria da Norma Tributária. São Paulo: Lael, 1974.

ESPÍRITO SANTO. Decreto $n^{\circ}$ 1.090-R. Disponível em: <http://www.sefaz.es.gov.br/>. Acesso em: 3 out. 2017.

KFOURI JR., Anis. Curso de Direito Tributário. 3. ed. São Paulo: Saraiva, 2016.

MACHADO, Hugo de Brito. Curso de Direito Tributário. 22. ed. São Paulo: Malheiros Editores. 2003.

MOUSSALLEM, Tárek Moysés. Curso de Especialização em Direito Tributário: Fontes do Direito Tributário. Rio de Janeiro: Forense, 2005.

PAULSEN, Leandro. Curso de Direito Tributário: completo. Epub. 6. ed. Porto Alegre:

Livraria do Advogado, 2014.

ROSA, Taís Hemann da. Direito fundamental social de acesso à energia elétrica:

apontamentos iniciais sobre a perspectiva brasileira. In: Seminário Internacional de Ciências Sociais e Ciência Política. 3., 2014, São Borja. Anais... Disponível em:

<http://cursos.unipampa.edu.br/>. Acesso em: 17 fev. 2017.

SABBAG, Eduardo. Manual de Direito Tributário. 9. ed. São Paulo: Saraiva: 2017.

SEGUNDO, Hugo de Brito Machado. Código Tributário Nacional: anotações à Constituição, ao Código Tributário Nacional e às Leis Complementares 87/1996 e 116/2003. 6. ed. São Paulo: Atlas, 2017.

TILBERY, Henry. Direito Tributário Atual. Ed. IBDT e Resenha Tributária, v. 10, 1990, n.p. 